\title{
Becoming an emergency resident: a program director's perspective
}

\author{
Bill McCauley, MD, MHPE
}

See also page 51.

\section{Introduction}

The process of recruiting medical students into emergency medicine (EM) residency programs has evolved over time. Knowing that EM is a competitive specialty, many program directors took the attitude that medical students were fortunate to be granted an interview. There was less competition for residents and more of a sense that medical students were barely worthy of applying to our programs, let alone being offered interviews.

Thankfully times have changed! Although competition for positions remains high, residency directors and educators have come to realize that they are no longer in the driver's seat - rather, that they must actively market themselves and their programs to attract the best of the best. The fact is, competition among program directors has become fierce. Despite an attitude of respectful cooperation, there is a healthy rivalry between programs, and all want to attract the best students. This is evidenced by the dramatic improvement in Web sites across the country whose purpose is to capture the interest of medical students. At the same time, there is fierce competition among medical students for residency spots. The following describes one program's approach to weeding through the candidates in order to find the healthiest flower.

Students must clear two main hurdles after deciding upon EM as a career. The first is assembling an application package that is attractive enough to win an interview. Although some programs interview anyone who is interested, most will screen applicants because resources simply don't allow interviewing every applicant. The second hurdle is the interview itself.

\section{Hurdle One: Getting an interview}

The first step in our process is to determine the number of candidates we will interview. This depends entirely upon the number of positions we have available each year. Usually we have two positions available, but some years only one. In the good years, when we have two positions, we typically interview 18 candidates; in the other years, depending on the quality of the applicant pool, we interview 12 to 15 . We interview the best candidates, irrespective of where they are from; however, if there are applicants from our medical school who don't make the initial interview list, we often offer them an abbreviated interview following our formal interview day.

The program director, 4 to 6 faculty members and at least 2 residents review the files of all applicants. We use a scoring system to ensure consistency. The scoring system gives the applicants "marks" in each of several domains, including interest in academic EM, elective experiences, reference letters, as well as the applicant's personal letter and academic achievements. In our program, the scoring is

Program Director, Royal College Residency in Emergency Medicine, University of Western Ontario, London Ont.

Received: Oct. 5, 2003; final submission: Nov. 5, 2003; accepted: Nov. 21, 2003

Can J Emerg Med 2004;6(1):53-4 
weighted heavily toward academic interest, EM electives and reference letters. These three domains make up approximately $80 \%$ of the overall score. We place little emphasis - only 10 of 100 marks - on academic achievement, and most students will score 8 to 10 on this section. Once each reviewer has scored every file, we tally the scores, average them, and generate an initial interview list. Although this list forms the framework by which we shortlist candidates for interviews, we will make some adjustments based on our personal knowledge of the candidates. For example, if a candidate has done an elective with us, yet was ranked 19 on our list of 18, that candidate may be given an interview.

Clearly, for our program, students need to ensure that their files will score highly enough to be short-listed. Knowing that the most heavily weighted areas are electives, academic interest and reference letters, savvy students will have applications that are strong in these areas. That being said, what the program is really doing is applying a number to desirable qualities that most programs look for in a resident. Sadly, our program does not have the capacity to interview all applicants. Every year we receive calls from disappointed candidates wondering why they were not interviewed. Although it is small consolation, we believe that our scoring system is relatively objective and, as such, fair to all candidates.

\section{Hurdle Two: The interview}

Once the interview list is created, the slate is wiped clean and we start all over again. The purpose of the interview is to meet candidates face to face, get a feel for what they are like, and eliminate applicants who seem like a poor "fit" for our program. Our interview format is such that every interviewer meets with every candidate. We have three interview rooms: two rooms with two faculty members and a resident, and one room with all residents. Each faculty interviewer generates a rank list at the end of the day based on overall impression of the candidates. The residents collectively generate one rank list between them. At the end of the day all interviewers meet and average the scores to develop an overall rank list. We use this as a starting point to make our final decisions. However, residents and faculty both hold "veto power" if there are candidates that they feel would not do well.

Although the candidates' academic achievements and elective experiences in EM play a role in this ranking process, the most important part of the interview is how the candidates get along with the faculty and residents. Our primary concern is determining whether or not we can develop a positive, productive and enjoyable working relationship with those at the top of our rank list. Interestingly, year after year, the list at the end of our interview day is strikingly similar to the list that was generated at the end of the file review process.

\section{E-CaRMS}

The introduction of the E-CaRMS (Electronic - Canadian Residency Matching Service) process last year raised a number of concerns from both students and programs. Despite this, the E-CaRMS process worked relatively well for us. Certainly, there were issues related to the speed of file access depending on your location when accessing the files, as well as the "readability" of several documents; however, the overall process was efficient and we are looking forward to using the system again because we believe it is fair to both medical students and programs.

\section{Summary}

The E-CaRMS application process is stressful for both students and programs. The bottom line is that programs and medical students want the same things. Programs want students who are keen, bright, eager, hard working and motivated to learn EM. They also want students who are enjoyable to be around and who have a broad range of non-medical interests. Students want programs that are keen, eager and excited to teach EM. Students also want programs with faculty who are enjoyable to be around and respectful of them as residents. In general, the E-CaRMS process allows students and programs to be matched together to everyone's satisfaction.

Key words: residency; emergency; application

Correspondence to: Dr. W.A. McCauley, Division of Emergency Medicine, London Health Sciences Centre, Victoria Campus, 391 South St., London ON N6H 4G5; wmccaule@uwo.ca 